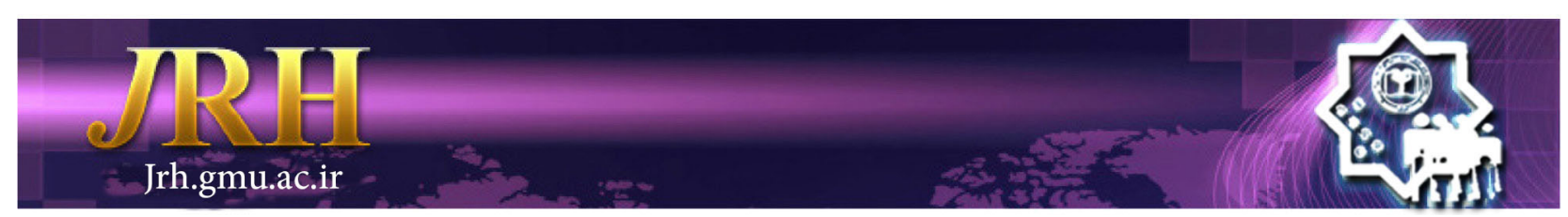

\title{
The mediation role of quality of work life in the relationship between information cancer and learning process
}

Roya Arjmand Kermani ${ }^{1}$, Mohammad Khaledian ${ }^{1}$

\author{
Journal of Research \& Health \\ Social Development \& Health Promotion \\ Research Center \\ Vol. 9, No.4, Jul \& Agu 2019 \\ Pages: $337-346$ \\ DOI: $10.29252 /$ jrh.9.4.337 \\ Original Article
}

1. Department of Psychology, School of Psychology, Payame Noor University, Tehran, Iran

Correspondence to: Roya Arjmand Kermani, Department of Psychology, School of Psychology, Payame Noor University, Tehran, Iran

Email:ro.arjomand@gmail.com

Received: 10 Mar 2018

Accepted: 9 Apr 2019

How to cite this article: Arjmand Kermani R, Khaledian M. The mediation role of quality of work life in the relationship between information cancer and learning process. J Research \& Health2019; 9(4): 337- 346.

\begin{abstract}
New technologies have increasingly facilitated information production process and also have made it possible for many people to access to a large amount of information. This causes information cancer phenomenon in which the information destroy resources, facilities, and human labor aimlessly and destructively. This study has been considered to investigate the relationship between the phenomenon of information cancer and learning process according to quality of work life as a mediation variable. 148 participants were and they are selected according to a simple random sampling method. Tools for data collection were three questionnaires- questionnaire of Walton's quality of work life, questionnaire of Kolb's Learning Styles and questionnaire of information cancer - that were used by the sample after the examination of nominal validity and reliability of questionnaire of work quality, learning process and information cancer by the help of Cronbach's alpha coefficient with following values: 0.862 , 0.926 and 0.903 and affirmation of their confidence. The findings showed that there is a significant relationship between information cancer with the quality of work life and learning process in the confidence level. Also there is a significant relationship between quality of work life and learning process in the confidence level. The results of the research showed that this limit of confidence distance mentioned the significance of the indirect path of the primary model. It became clear that the quality of work life plays a mediation role in the relationship between information cancer and learning process of personnel.
\end{abstract}

Keywords: Cancer, Learning Process, Quality, Work Life

\section{Introduction}

Inquisition about learning process is among the main discussions that guide us to the desired learning. Process and method of learning are defined as individual ways used by the learners to process new information and concepts or ways that learners organize information with the help of them. One of the most efficient approaches during the survey of people's learning level is Kolb's learning process. In conformity with the Kolb's theory, learning is a four-step process and consists of eye experiment, deliberative observation, abstract conceptualization, and active testing. According to the Kolb and Fry's statement, learner needs four types of abilities that are mentioned above-i.e. learner should be able to 
intermix with the new experiments completely, willingly and without any orientation, be able to observe these experiments from different points and deliberate about them, be able to make concepts that can mix theories which are true from the rational aspects and uses these theories for decision-making and solving problems [1]. Experimental Learning Method (ELM) that was propounded by Kolb is among the cognitive models of information processing and is known as one of the models of organization and processing of information [2].

In the current complicated environment, people face with affluent information and should have proper skills to separate reliable information from abundant amount of existing information [3]. So, while information plays a vital role in the management and organization process, information overload or in other words information cancer is among the disturbance causes in the organization planning. All organizations need information for survival in the business and competition market while extra information can deluge those organizations in themselves. The existence of wrong and repetitive information leads to the people's disillusionment and prevent them from access to useful and beneficial information. With the increase of information, need to the analysis will increase too and sometimes inordinate analysis will conduct to the paralysis and can harm the right decision making power [4]. From the Herbing \& Kramer point, during formation of the phenomenon of information cancer, the abundant amount of information present in a short time span and thereby their perception and solving them will be difficult for most people. Information overload normally occurs when the nature of information is ambiguous, unspecified, new, complex or condensed. Information overload causes augmentation of data and weakness of information [5]. James Meyer has considered the phenomenon of information overload as one of the information traits that result to the increase of information processing capacities [6]. In contrast, information accumulation (information overload) probably will not lead to the information transition, except under special conditions that receptor can't use or observe all his/her necessary information [7]. Herring treats efficiency increase as another reason for demanding more information. Following the information increase, the level of satisfaction and psychic mode of decisionmakers as well as their self-confidence, will increase during their decision-making. In other words, reliance on the excess amount of information has positive effects on the levels of self-confidence and satisfaction of decision-maker [8]. Carlson defined stress as a kind of feeling that raised from the anxiety of information overload increase. The main influential factors on the formation of information overload that lead to the stress are as following; psychic pressures (as: air, heat, working in the night shift, hard physical work and...), psychology pressures (as: time deficit, challenges, social isolation, compulsory group workings and lack of recognition) and financial pressures (as: budget deficiency, lack of work confidence and information flowage) [9]. Mengis \& Eppler suggested that mutual action against the information overload should be done in conformity with five widespread subjects - personal factors, information characters, work and processing parameters, organizational design and using information technology [10]. Sax believes: it is my attention to the excess information that is especially estimated and evaluated. This is essential during adjustment and control of main and necessary excess information. You should remember that knowledge and information are considered as a stimulant and primary source to gain work success [11]. Acquisition of useful information is also a good way and if you want to gain success, you should develop the skills of "evaluation as research- oriented "in the related organization [12].

So information cancer describes conditions that under these terms, information is stray in the organization causelessly and anarchically and resultant energy will waste too. In other 
words, information interchange in such society is done anarchically and is far from using proper logic and since such collections haven't enough power to interchange with each other and the external world, so they eventually will turn into uncontrollable information tumors and will show inverse effect [13]. And this matter is very important for different organizations and particularly universities that are the main source of producing documentary information. Managers and personnel of universities suffer this kind of information dispersion and the phenomenon of information cancer will form under these conditions and finally, information will manifest causelessly and destructively and will lead to the waste of resources, facilities and human power. Phenomenon of information cancer relates with different influential factors and this paper tried to study the relationship between phenomenon of information cancer with quality of work life and learning process of personnel of Payam-e Noor university of Qazvin province. According to an eloquence point, quality of work life of personnel is one of the decisive factors during evaluation and deliberation of organization position. The contemporary organizations with strategic look to the human benefits treat it as a valuable and intelligent possession and increasingly pay attention to the improvement of quality of life and work satisfaction of their personnel. The psychic needs of personnel in the organizations are met via using tactics of quality of work life [14]. So quality of work life is a process that personnel can learn from it how work with each other trustfully and analyze the operations till can fulfill the aim of improvement of personnel's work life quality and organization effectiveness simultaneously [15]. This plan of quality of work life consists of all kinds of improvement in the organizational culture [16] - that is the supporter of growth and sublimation of personnel in the related organization. Hence the value system of quality of work life seriously notices the investment on the people as the main variable in the equation of strategic management - i.e. fulfillment of personnel needs will lead to the long term reform and proficiency of organization [17]. Quality of work life consists of personnel cognizance of their physical (corporal) and psychic (intellectual) hygiene in the work environment and its main factors are personnel participation, work improvement, conflict solving, relationship, health, work security and honorific and safe work environment [18]. "Hacman" and "Sotel" mentioned that the strategies which are used by most organizations to improve the life quality [19] as follow;

1) Codification the work path of planning the function of salary and premium system.

2) Planning and preservation of intergroup and intragroup relationship.

3) Management measures and operations.

4) Intrinsic and extrinsic guidelines for communication.

Other guidelines that can improve the quality of work life of personnel are as following: increasing the level of humanity of work, efficient leadership and supervision behavior, developing progress path, flexible work schedules and modernization of organization structure [20].

Quality of work life is a concept that shows the balance between personal life and professional life of a person. This concept is among the numerous ways to think about people, work and organizations and also makes a kind of administrative concept in the mind of personnel. This component also helps forming work satisfaction, productivity improvement, adaption and increasing the level of organization efficiency [21]. The concept of quality of work life is defined as the amount of person ability during fulfillment of personality and principal needs via what they have learned from the related organization and relates with the personal fidelity, tone of office leaning, the level of efficiency of organization and life quality [22].

It seems that life quality index relates to the learning process of personnel such as human characteristics and special talent during the learning process. We can certainly say that the genesis and survival of civilization and the 
culture of human are the resultant of learning talent and one of the main factors of social development in the human life is learning. Learning subject is among the most important discussions in the psychology domain and at this basis every human can improve skills and human developments and ever-increasing increment of science is primarily the born of learning. Recent research findings in the learning science and cognitive sciences - in order to answer this question that how people can learn new skills - mostly rely on the mind functions during deep learning and making knowledge inside the learner [23]. According to this view, learning is a process that every person can improve mental representative via this process [24].

\section{Method}

In this study, conducted in 2017, the statistical population of current research consists of 240 personnel of Payam-e-Noor university of Qazvin province, central district of Iran (150 males and 90 females). Cochran's formula is used for the sample size and thereby the sample size has been estimated as 148 participants. After preliminary survey and studying the related resources and researches, a questionnaire and its corresponsive criteria were prepared. The study questionnaire consists of three parts: the first part includes questions about the information cancer. A verified questionnaire was used for this purpose. This questionnaire has 15 items that has been developed inversely on the basis of 5-Likert scale. The second part includes items about the quality of work life. The questionnaire of quality of work life of Walton was used for this purpose. This questionnaire has 24 items and is designed on the basis of 5-Likert scale. The three parts includes questions about the learning process according to the Kolb Theory. This questionnaire has 12 questions and offers 4 answers for each question. Offered answers are graded in the range of 1-4.

Nominal or symbolic justifiability is used for determination of level of questionnaires justifiability. Then the opinions of professors and clear-sighted persons are included in the questionnaire and if necessary they would change. As the questionnaire of quality of work life of personnel is a standard one, so this test has a high level of reliability.

Cronbach's alpha test is used for testing the reliability of questionnaires in the current study. Thereby the research society was evaluated by a preliminary study upon 30 participants of university personnel. By SPSS-21, the findings showed that the level of reliability of questions about the information cancer, quality of work life and learning process $0.903,0.862$ and 0.926 was respectively determined.

The collected questionnaires in the illative level were used to analyze the final data and software Amos Graphics was also used for testing research hypotheses and to perform the process of searching-model of structural equations. The process of structural equations was actualized in conformity with a twostep approach that was offered by Anderson Gerbing. Thus 10 measurement models (information cancer, fairly payment to the personnel, the security of work environment of personnel, providing growth opportunity and constant safety, following the law by the people, social coherence of personnel, general atmosphere of personnel work, social integration of personnel, developing personal potencies of personnel and learning process) were firstly estimated and tested. Meantime in this step, significance and meaningfulness of every agent loads were evaluated in the measurement models, convergent validity was studied too. Then in the second step, structural models were fitted by a simple and plural regression technique.

\section{Results}

Structural equation model in this study includes three main hypotheses. In conformity with the estimated results and testing verified agent models, it becomes clear that all ten models in the measurement model are supported by the collected data. Thus the necessary condition for estimating and testing models of structural equation of this study is fulfilled. 
Table 1 Means and standard deviation of variables

\begin{tabular}{lcc}
\hline Variables & Mean & S.E. \\
\hline Information cancer & 3.6143 & 0.65614 \\
Quality of work life & 1.5641 & 1.17394 \\
Learning process & 2.0137 & 0.92178 \\
\hline
\end{tabular}

Table 2 Fit indexes of structural equation model of explainer of relationship of research variables

\begin{tabular}{lcccccc}
\hline Indexes & $\mathrm{p}$ & $\mathrm{CMIN} / \mathrm{DF}$ & $\mathrm{IFI}$ & $\mathrm{TLI}$ & CFI & RMSEA \\
\hline $\begin{array}{l}\text { Hypothesis 1: information cancer and quality of work } \\
\text { life }\end{array}$ & 0.000 & 3.357 & 0.862 & 0.916 & 0.872 & 0.077 \\
$\begin{array}{l}\text { Hypothesis 1: information cancer and quality of work } \\
\text { life - modified }\end{array}$ & 0.000 & 2.773 & 0.904 & 0.900 & 0.904 & 0.067 \\
$\begin{array}{l}\text { Hypothesis 2: quality of work life and learning process } \\
\begin{array}{l}\text { Hypothesis 2: quality of work life and learning process } \\
\text { - modified }\end{array}\end{array}$ & 0.000 & 3.798 & 0.869 & 0.858 & 0.869 & 0.084 \\
$\begin{array}{l}\text { Hypothesis 3: the phenomenon of information cancer } \\
\text { and learning process }\end{array}$ & 0.000 & 2.387 & 0.915 & 0.906 & 0.915 & 0.059 \\
\hline
\end{tabular}

According to the results of Table 2 regarding the models of hypotheses "1" and "2", at first two indexes-index of K -Normalized Squared and the second root of squared error estimate -confirmed the mentioned model in the confidence level. This model needed necessary modifications. After modification-according to the results regarding the mentioned model - all indexes confirmed the modified model except the index of K-Squared. Thereby due to the verification of models of structural equation and also significance of regression coefficients, hypotheses " 1 " and " 2 "are confirmed in the confidence level, i.e. in this level of confidence, the phenomenon of information cancer has an inverse significant and significant relationship with the quality of work life (with $27 \%$ coefficient) and quality of work life has a positiveand significant relationship with the learning process of personnel of Payam-e Noor university of Qazvin province (with $63 \%$ coefficient).

Also according to the results of Table 2 regarding the models of hypothesis "3", all fit indexes confirm the mentioned model in the confidence level except the index of $\mathrm{K}$-Squared. Thereby due to the verification of models of structural equation and also significance of regression coefficients, hypothesis " 3 " has been confirmed in the confidence level, i.e. in this level of confidence, the phenomenon of information cancer has a significant relationship with the learning process of personnel (with $42 \%$ coefficient)and as this coefficient is negative so this is an inverse relationship.

Table 3 Correlation coefficients of hypotheses

\begin{tabular}{lcccc}
\hline Variables & $\begin{array}{c}\text { Standard coefficient } \\
\text { (correlation coefficient) } \\
\text { S.R.W }\end{array}$ & $\begin{array}{c}\text { Critical ratio } \\
\text { C.R }\end{array}$ & p-value & Test result \\
\hline Information cancer and quality of work life & -0.27 & -4.7080 & 0.001 & Verified \\
$\begin{array}{l}\text { Quality of work life and learning process } \\
\begin{array}{l}\text { The phenomenon of information cancer and } \\
\text { learning process }\end{array}\end{array}$ & 0.63 & 9.712 & 0.001 & Verified \\
\hline
\end{tabular}


According to the results of Table 3, absolute value of C.R (critical ratio) of relationship between information cancer and quality of work life (4.708), C.R (critical ratio) of relationship between quality of work life and learning process (9.712) and absolute value of C.R (critical ratio) of relationship between information cancer and learning process (6.733) is more than 1.96 as well as p-value is less than 0.05 , so there is a significant relationship between the variables (information cancer and quality of work life, quality of work life and learning process and the phenomenon of information cancer and quality of work life) in the confidence level.

Figure 1 shows the research general model.
In conformity with the results of Table 4 regarding the mentioned model; all fit indexes except the index of K- Squared confirmed this model in the confidence level. Thus due to the verification of models of structural equation and also significance of regression coefficients, the research general model is confirmed in the confidence level 95, i.e. in this level of confidence there is an inverse relationship between information cancer with quality of work life of personnel and learning process (with coefficients: -0.27 and -0.28). Also there is a positive relationship between the variable of personnel's life quality and learning process of personnel (with coefficient 56).

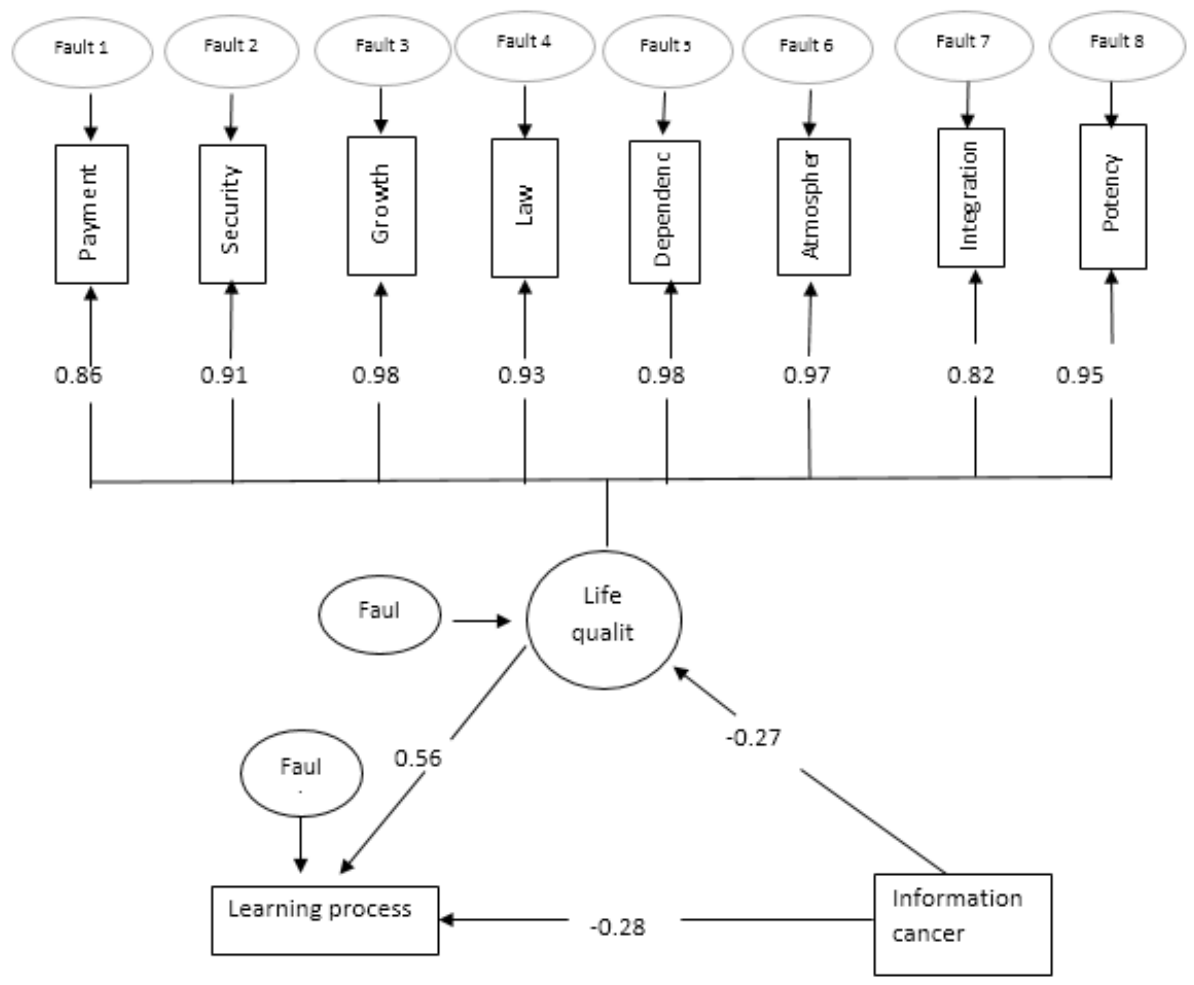

Figure 1 Model of general structural equation of research

Table 4 Fit indexes of research general model

\begin{tabular}{lcccccc}
\hline Indexes & $\mathrm{p}$ & CMIN/DF & IFI & TLI & CFI & RMSEA \\
\hline $\begin{array}{l}\text { Information cancer, quality of work life } \\
\text { and learning process }\end{array}$ & 0.001 & 2.401 & 0.910 & 0.901 & 0.911 & 0.060 \\
\hline
\end{tabular}

Also the results of Bootstrap performance during evaluating the path of information cancer / quality of work life / learning process of personnel show that lower limit of confidence distance in this path is 0.142 and its upper limit is 3.042. Nonexistence of zero in the distant confidence indicates the significance of this indirect path and hereon confirms the mediation role of variable of quality of work life of personnel in the relationship between 
two main variables - information cancer and learning process of personnel (the confidence level 95 and the number of Bootstrap samples were 20000).

\section{Discussion}

The results of testing research hypotheses show that in the hypothesis " 1 ", there is a significant relationship between information cancer phenomenon and quality of work life of personnel of Payam-e-Noor University of Qazvin province (with 27\% coefficient) and as this coefficient is negative, so it is an inverse relationship. In other words with increasing one unit in the information cancer phenomenon, quality of work life of personnel of Payam-e-Noor university of Qazvin province will decreases 27 units. The results of this hypothesis are consistent with the results of prior researches that are done by Arjmand Kermani and Abassi Astemal. They showed in their researches that there is a significant relationship between organizational structure and information overload (case study: Payame-Noor University). In this study the utmost effect on the changes of variable of information overload is justified by the changes of variable of organization formality [25]. It can be mentioned to the Norton viewpoint to analyze the results of this research hypothesis in this field. According to his viewpoint, the results of information overload are as following: 1) Stress and illness: owing to the information overload, one-third of people are affected with the illnesses that are the result of stress and neural pressures. 2) Less free time: two- thirds of people should work a long time to counter with the high level of information. 3) Less work satisfaction: 70 percent of people lose their work satisfaction due to the information overload. 4) False decision making; almost 43 percent of people believe that information overload has an unfavorable effect on their decision making potency [26].

In the hypothesis "2", there is a significant relationship between quality of work life and learning process (with 63\% coefficient). In other words, it can be said that if quality of work life increases one unit, learning process will increase 63 units. The results of this hypothesis are correspondent with the results of prior researches that are done by Amrahi and et al. They showed in their researches that there is a significant direct relationship between quality of work life and organizational learning. Thereupon it can be observed according to the different dimensions of quality of work life of personnel that organizational learning has increased among them [27]. For explaining this result, we can mention to the Chard viewpoint. Also in conformity with the Chard viewpoint, the signs of information overload are as following: weak concentration owing to the overload of short time memory, speed malady - man believes that should race with the time, multipurpose behavior due to the vest production or marginal production power, enmity due to the acute mood, ability of stimulating anger or dementia or worn or provocation that lead to the closing or shutting of brain [28].

Also the results of the hypothesis " 3 " showed that there is a significant relationship between information cancer phenomenon and learning process (with 42 percent coefficient) and as this coefficient is negative, so it is an inverse relationship. In other words, if information cancer phenomenon increases one unit, learning process of personnel will decrease 42 units. These results are correspondent with the results of researches of Sadeqi and Mohtashami who studied the role of ultrarecognition during the learning process. After explaining the results of this research hypothesis, it can be said that personnel should spend less time for finding their necessary information during doing their works in the related organization and thereby pave the way for improvement of personnel's learning process. So in order to access the necessary information, easy access to all information sources is vital and organizations should try to use all the information that have received on the same day for investigating and making right decisions at the same time of that day and all personnel should also receive essential 
instructions about receiving, processing, sending and appropriate use of information. Ultra-recognition describes the level of comprehension talent and control process of under-learning materials and plays a vital role during the improvement and development of recognition operations and can develop the learning skills of learners. They declared that ultra-recognition plays a substantial role during successful learning and with the improvement of recognition abilities of the learner, the level of success of the learning process will increase too. In other words, the learner should play actively in learning process and learn also to evaluate learning level and if learning guidelines are not successful, he/she should employ the new guidelines. So teaching ultra-recognition skills to the learners has a considerable effect on the level of lessons learning [29].

This study faced with many limitations like lack of similar researches in the field of information cancer or related to this subject in Iran as well as other countries and newness of this matter. After searching in the scientificresearch bases and different internal sites and searching in the inward and outward creditable magazines, we hadn't found any research with the subject of mediation role of quality of work life in the relationship between information cancer and learning process - whether inside of Iran or outside of Iran - and for this reason we couldn't find enough history and the current study is among the first researches in this field. In the end, as results show that phenomenon of information cancer has a significant relationship with the quality of work life and learning process of personnel. so we offer new administrative guidelines for decreasing the probability of forming the phenomenon of information cancer and improvement of quality of work life and learning process of personnel of Payam-e-Noor University of Qazvin province:

1) It is necessary for improvement of quality of work life of personnel that the university authorities try to pay the personnel salary in conformity with their work and their logical and equitable work times. Work environment should be designed with more attention to the sanitary principles. University authorities should accrete the conditions for the employment of educated new skills and personnel should have right perception of organizational goals and aims.

2) For improving the learning's level of personnel of Payam-e-Noor University of Qazvin province, eschewing the reception of unrelated information is as possible necessary since it leads to the waste of time during orders execution and drowning in the excess information. For this reason, university should try to eliminate the over plus and additional information by the codified information forms by different sections and uses new information technologies for easy and quick access and runs the classification and organization system and paves the way for quick control of information in the general status for optimum use of input data and elimination of over plus information.

3) Disposing training courses in the field of collection, classification, organization, edition and control of information in order to eliminate over plus information and improvement of learning process.

\section{Conclusion}

In this direction, this study is performed for evaluation of relationship between information cancer with the quality of work life and learning process of personnel of Payam-e-Noor University of Qazvin province. According to the results of research, it can be said that there is a significant and negative relationship between information cancer phenomenon and learning process. This relationship is mediated by the variable of quality of work life and helps to the decrease of negative severity of this relationship in such a manner that in the indirect path of information cancer/ quality of work life / learning process, information cancer than direct path of information cancer / learning process rarely leads to the decrease of personnel's learning process.

So it can be concluded that information cancer is a serious obstacle for improvement 
of quality of work life and learning process of personnel and for this reason it can be said that quality of work life can play a vital mediation role in the relationship between quality of work life and learning process.

\section{Authors' contributions}

Study design: RAK

Data Collection and Analysis: RAK, MK Manuscript preparation: RAK, MK

All authors have read and approved the final version

\section{Acknowledgements}

The authors would like to thank honorable presidency of Payam-e-Noor University of Qazvin province and all faculty members and personnel who had kind cooperation in the process of this research.

\section{Conflict of Interest}

"The authors declared that they have no competing interests."

\section{Funding}

The author (s) received no financial support for the research, authorship and/or publication of this article.

\section{Availability of data and materials}

The datasets used and/or analyzed during this study are available from the corresponding author on reasonable request.

\section{Results}

1- Seif Ali A. New training psychology: psychology of education and learning. Tehran: Duran publisher; 2016.

2- Arab Mazar M, Maseihabadi A, Pouryousof A. Auditor's cognitive style, information load and judgment quality in going concern. Journal of Accounting and Auditing Review2012; 19(68): 73-96.

3- Azad Pile'rood L. An investigation into information literacy of academic staff of departments of librarianship in government and non-government universities in Tehran and its impact on their creation of scientific information. Journal of National Studies on Librarianship and Information Organization2008; 19(1): 213-28.

4- Norton B. Handling information overload. Translate by Nik Fetrat B, Emami MH. Tehran: Quality and management publication; 2003.
5- Herbig PA, Kramer H. The effect of information overload on the innovation Choice. Journal of Consumer Marketing1994; 11(2): 45-54.

6- Meyer J-A. Information overload in marketing management. Marketing Intelligence \& Planning1998; 16(3): 200-9.

7- Klausegger C, Sinkovics R. Information overload: a cross-national investigation of influence factors and effects. Marketing Intelligence \& Planning2007; 25(7): 691-718.

8- Hering FJ. Informationsbelastung in entscheidungsprozessen: experimental-untersuchung zum verhalten in komplexen situationen (schriften zur empirischen entscheidungs- und organisationsforschung). Vienna: Peter Lang; 1986.

9- Carlson ChN. Information overload, retrieval strategies and Internet user empowerment. In the good, the bad and the irrelevant (COST 269), Helsinki (Finland), 2003 Sep 3 - 5. Germany, Göttingen: eprints in library \& information sciences: 2003.

10- Eppler MJ, Mengis J. The concept of information overload: A review of literature from organization science, accounting, marketing, MIS, and related disciplines. The Information Society2004; 20(5): 325-44. 11- Sax B. Storytelling and the "information overload". On the Horizon 2006; 14(4): 165-70.

12- Landale A. Hunter-seeker strategies: the antidote to overload. Industrial and Commercial Training2007; 39(4): 227-30.

13. Ghane Bassiri M. From information to knowladge. Theory of three-point balance. Tehran: Reflection of Thought 1994.

14- Payne RL. Eupsychian management and the millennium. J Manage Psychol2000; 15(3): 219-26.

15- Shokrolahi A, Taheri, A. The relationship between quality of Work life and organizational citizenship behavior with employee entrepreneurship. New Approach in Educational Management2015; 6(4): 130.

16- Dockel A, Basson JS, Coetzee M. The effect of retention factors on organisational commitment: An investigation of high technology employees. $S A$ Journal of Human Resource Management2006; 4(2): 20-8.

17-Richard B. Predicting the organizational commitment of marketing education and health occupations education teachers be work related rewards. Journal of Industrial Teacher Education2007; 32(1): 1-14.

18- Cascio WF. Managing human resourcesproductivity. New York: Quality of Work Life, Profits, McGraw-Hill, and Boston, MA; 1998.

19- Bazaz Jazayeri A, Pardakhtchi MH. Designing a model for assessing the quality of work life in organizations. Journal of Management Sciences of Iran2007; 2(5): 123-51. 
20- Noroozi M. A survey of the nature, approaches and strategies for improving quality of work life in organizations. Culture and Administrative Behavior2013; 7(5): 17-21.

21- Lourak Agh Z, Nazari AM, Rasouli M. The effectiveness of relationship of enhancement program on quality of work life (QWL). Iranian Occupational Health Journal2017; 14 (1): 156-164.

22- Abdollahzade F, Asghari E, Asghari Jafarabadi M, Mohammadi F, Rohani A, Mardani-Kivi M. Predictive factors of quality of work life among operating room nurses in training hospitals. Journal of Guilan University of Medical Sciences2016; 25 (99): 57-68.

23- Cassidy S. Learning styles: an overview of theories, models and measures. Educ Psychol2004; 24(4): 419-44.

24-Izadi S, Mohammad Zadeh Edema RA. The relationship between learning styles personality characteristics and academic performance of students. Daneshvar (Raftar) Shahed University2007; 14(27): 16.
25- Arjmand Kermani R, Abbasi Astmal MR. investigating the relationship between organizational structure and information overload (Case study: Payame-Noor university). Shiraz: International Management Conference: Challenges and Solutions. 2013. pp: 9.

26- Griffiths A, Norton B. Handling Information overload in a week (successful business in a week). London, UK: Hodder \& Stoughton; 1999.

27- Amrahi A, Ghalavandi H, Sayed Abbaszadeh MM. Study of the relationship between the quality of work life and organizational learning among employees of Urmia university. Quarterly Journal of Leadership and Educational Administration2014; 8(2): 9-26.

28- Chard P. Information overload: are we technology's masters...or servants? World At Work Journal2002; 11(3): 17-24.

29- Sadeghi Z, Mohtashemi R. The role of metacognition in learning process. Scientific Journal of Education Strategies in Medical Sciences2011; 3(4): 143-8.

\footnotetext{
Copyright $(\mathcal{C}) 2016$ ASP Ins. This open-access article is published under the terms of the Creative Commons Attribution-NonCommercial 4.0 International License which permits Share (copy and redistribute the material in any medium or format) and Adapt (remix, transform, and build upon the material) under the Attribution-NonCommercial terms.
} 